\title{
CHARACTERIZATION OF THE FROST HEAVE DEFORMATIONS IN HIGH LATITUDE AND DEEP SEASONALLY FROZEN SOIL OF INNER MONGOLIA WITH SENTINEL-1 INSAR OBSERVATIONS
}

\author{
T. Qu ${ }^{1,2}, \mathrm{H}$. Zhang ${ }^{3, *}, \mathrm{~F} . \mathrm{Niu}^{4}$, X. Shi ${ }^{5}, \mathrm{Z} \mathrm{Li}^{6}$ \\ ${ }^{1}$ College of Engineering, Peking University, Beijing 100871, China - tengteng.qu@pku.edu.cn \\ ${ }^{2}$ China-Pakistan Joint Research Center on Earth Sciences, Islamabad 45320, Pakistan \\ ${ }^{3}$ Inner Mongolia Transport Construction Engineering Quality Supervision Bureau, Hohhot 010051, China - hhhtzhw@163.com \\ ${ }^{4}$ State Key Laboratory of Frozen Soil Engineering, Cold and Arid Regions Environmental and Engineering Research Institute, \\ Chinese Academy of Sciences, Lanzhou, Gansu 730000, China - niufujun@1zb.ac.cn \\ ${ }^{5}$ School of Geography and Information Engineering, China University of Geosciences (Wuhan), Wuhan 430078, China - \\ shixg@cug.edu.cn \\ ${ }^{6}$ COMET, School of Engineering, Newcastle University, Newcastle Upon Tyne NE1 7RU, UK - zhenhong.li@newcastle.ac.uk
}

Commission III, WG III/9

KEY WORDS: Frost Heave, Seasonally Frozen Soil, Time Series InSAR, Sentinel-1, Deformation Monitoring, Freeze-thaw

\begin{abstract}
:
Global warming in recent years led to significant permafrost degradation worldwide. Accurate monitoring and comprehensive characterization of the deformation process in seasonally frozen soil is of great importance for constructions in cold regions in China. This work concentrates on the deformation laws and spatio-temporal characteristics of frost heave in high latitude and seasonally frozen soil of Inner Mongolia with time series InSAR observations. With 101 Sentinel-1 descending scenes that covered more than three freeze-thaw cycles for the study area along Shiwei-Labudalin Highway, this study realized the characterization of the frost heave deformations in seasonally frozen soil, and the analysis of the influencing factors of the hydrothermal process with the help of temperature and moisture data from in-situ monitoring. Time series InSAR observations show that most parts of the highway show obvious deformation with a displacement rate of around 30-60mm/yr. Especially, the deformation evolution in this seasonally frozen soil region changes with seasons, demonstrating a notable annual cyclical characteristic and seasonal activity. Moreover, time series in-situ monitoring data in deep underground boreholes not only further explains the deformation kinematics from InSAR observations, but also provide a better supplement for a more comprehensive mechanism understanding of frost heave deformations.
\end{abstract}

\section{INTRODUCTION}

With the increasingly severe trend of global warming, large area of permafrost degradation has occurred worldwide (Jin et al., 2007). The combination of permafrost degradation and human activities further induces permafrost thermal melting and frost heaving, and seriously threatens the engineering infrastructure and permafrost ecological environment in cold regions (Chang et al., 2015; Luo et al., 2014). Accurate monitoring and comprehensive characterization of the deformation process caused by frost heave is the core issue of studying the cyclic change of permafrost freeze-thaw erosion, and also the important content of determining the coupling of water, heat and force fields in permafrost. Especially in China, facing the major needs for the constructions in cold regions, it is very urgent to monitor and study the permafrost area where China-Mongolia-Russia Economic Corridor passes, which is of great scientific and practical significances.

Traditional permafrost deformation monitoring methods mainly rely on levelling, Global Positioning System (GPS), in-situ sensors and other in-depth field surveys (Hinkel et al., 2001; Wu et al., 2010; Zorigt et al., 2016), which is inefficient and time-consuming. Moreover, the observation density that can be achieved is limited, so it is difficult to carry out largescale deployments. Especially when the permafrost area is hard to reach for human, the ability of traditional observation techniques in deformation monitoring is significantly reduced. Especially, the conventional deformation monitoring is mostly based on point rather than surface, which cannot provide comprehensive and cooperative observation data for the analysis of deformation in permafrost area, hence cannot achieve the large-scale deformation monitoring. Compared with above, the Spaceborne Radar Remote Sensing could realize the macro dynamic monitoring of large area, and is not limited by the geographical location or human conditions. It is an important supplement to the traditional observation methods for permafrost monitoring. In particular, the differential interferometric synthetic aperture radar technique (D-InSAR) and time series InSAR technologies could monitor the surface deformation with the accuracy of $\mathrm{cm}$ or even $\mathrm{mm}$, which provides an efficient way to obtain the permafrost surface deformation. Many successful cases have been published, and a large number of achievements have emerged (Chen et al., 2012; Daout et al., 2017; Jia et al., 2017; Li et al., 2015; Zhang et al., 2019).

\footnotetext{
* Corresponding author
} 
Different from permafrost, seasonal frozen soil freezes in cold seasons and melts in warm seasons, which is greatly affected by external environment. The alternation of freezing and thawing cycles leads to significant differences of mechanical properties in this kind of soil. In cold seasons, water transfer and ice water phase change lead to the frost heaving in soil, while in warm seasons, settlement occurs after thawing. Under the actions of freeze-thaw cycles, the alternate occurrence of frost heave and thaw settlement is the remarkable feature of this kind of special soil, which is also the prominent problem that perplexes the engineering constructions in seasonal frozen soil regions.

Since middle last century, engineers and researchers have begun to pay attention to the phenomenon of frost heave in frozen soil (Cheng, 2001). However, most of these research results are aimed at permafrost area, and the research on seasonally frozen soil is relatively rare. Especially, the research on deformation laws and spatio-temporal characteristics of frost heave in seasonally frozen soil by InSAR remote sensing techniques needs to be further carried out.

Hence, this work focuses on the application of time series InSAR processing with Sentinel-1 TOPS datasets, to monitor and characterize the frost heave deformations in high latitude and seasonally frozen soil of Inner Mongolia. In the processing chain, 101 Sentinel-1 descending scenes are used which covers more than three freeze-thaw cycles from September of 2016 to April of 2020. The spatial and temporal evolutional characteristics of the frost heave deformations of seasonally frozen soil in the study area could be retrieved, and the influencing factors of the hydrothermal process with temperature and moisture data from in-situ observation stations are also analysed in details.

\section{STUDY AREA OF FROZEN SOIL REGION}

In this study, part of Shiwei-Labudalin Highway in Inner Mongolia Autonomous Region is selected as the experimental area. It's located in the northwest of Greater Khingan Mountain, with cold climate and abundant rainfall. It is a typical development area of deep seasonally frozen soil in high latitude in China. The permafrost here is mainly distributed in valley, flood plain and vegetation covered area in shady slopes. The thickness of permafrost is generally 2-5 meters, and the seasonal melting depth is large (Zhang et al., 2019). The water content of permafrost is high, being generally $35-65 \%$. The ground temperature of permafrost is high, hence it's in the degradation stage and extremely unstable.

Domestic researchers (Yao et al., 2017) found that, due to the effect of post freezing entropy, the surface soil moisture in the seasonally frozen soil area of Inner Mongolia Grasslands increased significantly under the actions of freeze-thaw cycles, which led to a severe impact on the frost damage in highway constructions.

Previous road field investigations show that due to the severe environmental impact of freezing and thawing cycle, extreme low temperature and alternation of dry and wet conditions in this area, highway diseases (Figure 1) are quite significant, which mainly include longitudinal crack of subgrade, frost heaving and frost thawing collapse of subgrade slope, etc.

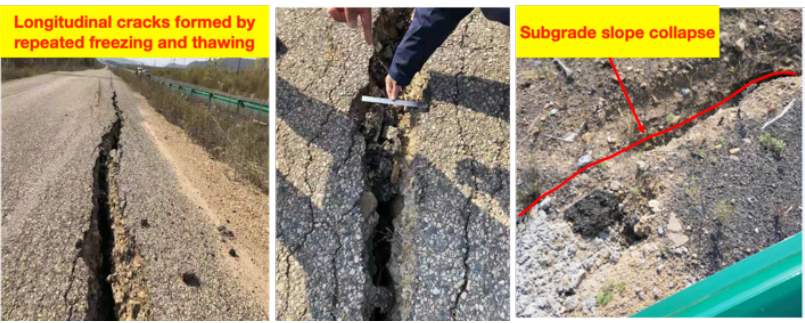

Figure 1. The frost heaving diseases of Shiwei-Labudalin Highway

\section{TIME SERIES INSAR PROCESSING AND ANALYSIS}

Permafrost often exist in high-latitude or high-altitude area, where time series InSAR applications would be seriously affected by atmospheric interference due to the large fluctuation of surface topography, numerous river valleys and abundant water vapor. Especially in rainy seasons, seasonal rainfall will cause serious atmospheric turbulence. Therefore, it is very important to accurately estimate and remove the atmospheric phase screens and further improve the reliabilities of time series deformation monitoring results.

As the atmospheric phase is a low-frequency signal in space domain and a high-frequency signal in time domain, it could be removed by filtering in time domain and space domain during the time series InSAR processing (Tang et al., 2016). Besides, the introductions of external data such as GPS, MERIS and MODIS water vapor data could significantly improve the correction effects of atmospheric artefacts ( $\mathrm{Li}$ et al., 2009a; Li et al., 2005). Moreover, when the terrain in the monitoring area fluctuates greatly or a large area is involved in the processing, the accuracy of atmospheric phase estimation could be further improved by combining elevationcorrelatedd linear models with filtering (Chang et al., 2014).

In our study, an atmospheric estimation model (Li et al., 2009 b) was deployed in time series InSAR processing, which significantly improves the accuracy of time series deformation results. In the processing chain, 101 Sentinel-1 descending scenes are involved dating from September of 2016 to April of 2020 , which covers more than three freeze-thaw cycles and ensures an adequately long evolution history for the monitoring and characterizing of seasonally frozen soil in the study area.

Figure 2 shows the annual displacement rates in study area. Thanks to the good scattering effects on the highway, good correlations could be achieved in most parts of subgrade during time series processing. Although a few parts of the highway remain stable in these years, most parts of the highway show obvious deformation with a displacement rate of around $30-60 \mathrm{~mm} / \mathrm{yr}$. This result reflects that the hidden danger of highway diseases is serious, hence this highway which passes through seasonally frozen soil needs to be monitored and maintained regularly. 


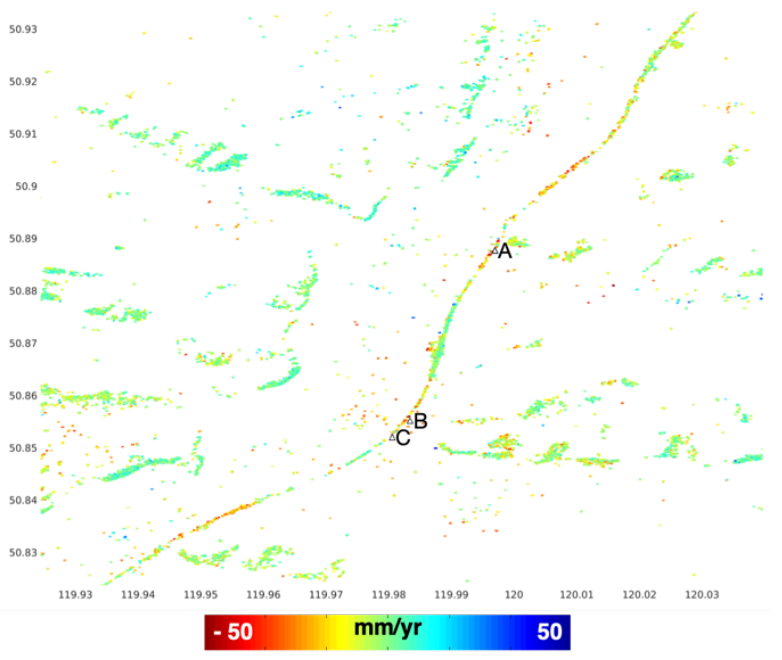

Figure 2. Deformation rate map derived from time series InSAR processing

The accumulated time series displacements for point A, B and $\mathrm{C}$ were then extracted in Figure 3. Thanks to the long evolution time span that covered more than three freeze-thaw cycles, time series InSAR deformation results of these three points show that deformation in this region changes with seasons, demonstrating a notable annual cyclical characteristic and seasonal activity. Although the deformation magnitudes are slightly different, the deformation evolution trends of the three points are almost the same.

After entering the cold season, from November of each year, the frozen soil began to show significant deformation, with the largest displacement rate in the whole freeze-thaw cycle. While at the end of January, the displacement rate gradually reduced. When coming to April of each year, apparent frost heave deformation occurs, which indicates that the maximum frost depth has reached. From late May every year, the frozen soil shows melting and sinking deformation again, and reaches the maximum value in July and August every year, then the subsidence deformation gradually recovers again until October. The melting period lasts for about 4 months, and the maximum deformation of melting settlement is much larger than the maximum frost heave in most cases except for point $\mathrm{C}$ in the third freeze-thaw cycle. Especially for point B which contributes the largest displacement rate in study area, almost continuous subsidence could be significantly observed from multiple freeze-thaw cycles. a)

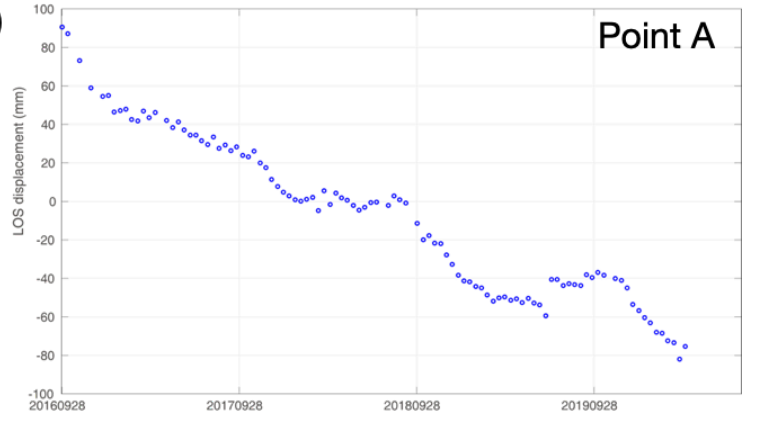

b)

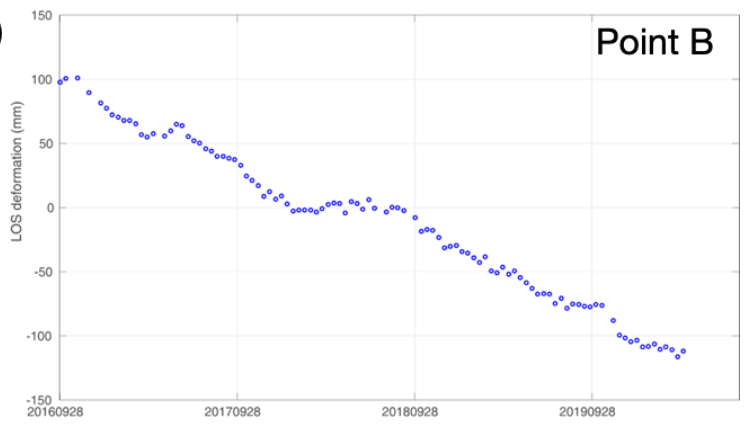

c)

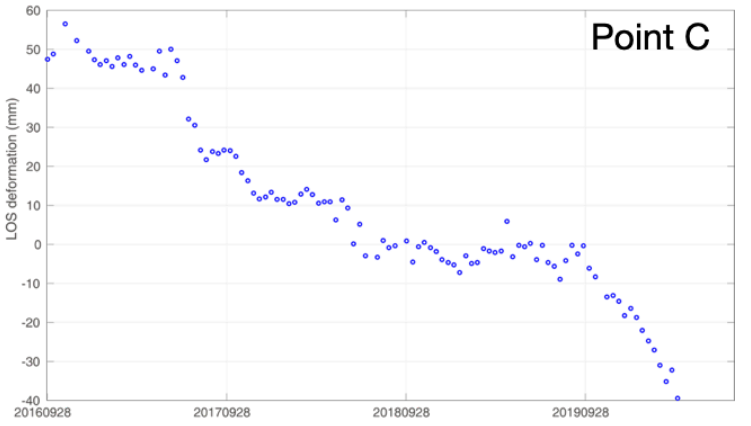

Figure 3. Time series displacement curves for point A, B and C respectively

\section{HYDROTHERMAL PROCESS FROM IN-SITU MONITORING}

The hydrothermal process of highway is the main cause of frost heave deformation. In order to analyse the mechanism of frost heave in details, the monitoring data of temperature and moisture from in-situ observation stations were extracted for analysis. These data were collected from the borehole deployed besides point $\mathrm{C}$ in Figure 2.

As shown in Figure 4, the temperature monitoring data indicates that the freezing period of frozen soil area starts from the end of October and lasts for nearly 180 days to the middle of April of the next year. In March of the second year, the maximum frost depth was reached, and the frost heaving would completely disappear in the end of July, which could further explain the deformation evolution retrieved from Sentinel-1 InSAR observations in the former chapter. Moreover, the figure could also illustrate that the frozen depth of frozen soil in this region is approximately between $2.2 \mathrm{~m}$ and $4.0 \mathrm{~m}$. 


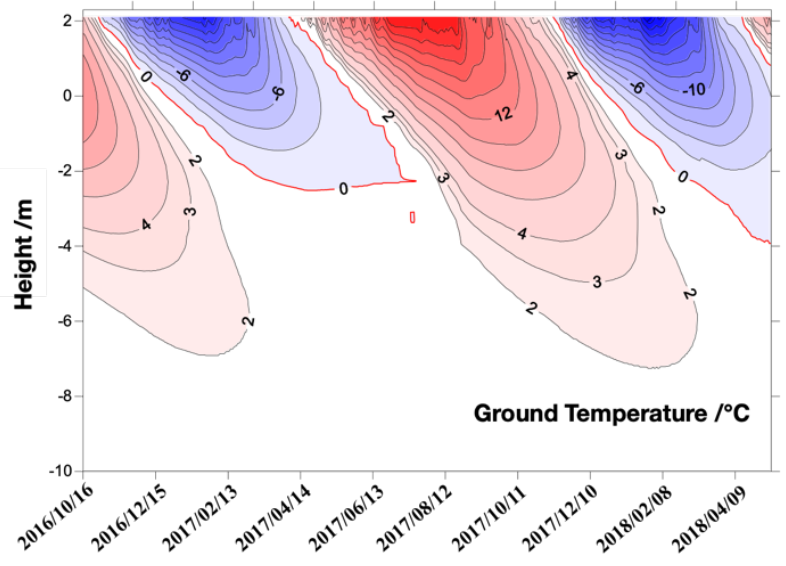

Figure 4. Subgrade freeze-thaw cycle revealed by temperature monitoring data

Water change is the main reason for frost heave deformations of deep seasonally frozen soil. Under the action of freeze-thaw cycle, water is constantly migrating, resulting in excessive water content in some area. It causes frost heave deformation after freezing in cold seasons, and volume reduction after thawing in warm seasons, hence resulting in settlement at last. Therefore, it is of great significance to grasp the spatiotemporal distribution characteristics of the moisture content in the subgrade, to reveal the frost heave development characteristics under the seasonally frozen soil surface.

Therefore, in order to further analyse the causes of frost heave, the moisture data in warm seasons from different depths in the borehole were extracted. In Figure 5, layer I, II, III, and IV represent the borehole depths of $0.10 \mathrm{~m}, 0.30 \mathrm{~m}, 0.62 \mathrm{~m}$, and $0.82 \mathrm{~m}$ respectively. From this figure, we could see that the water changing processes of each layer is basically the same. After entering the warm seasons, the pavement thaws gradually with the increase of temperature, and the liquid water content also increases. In layer III, the highest water content can be more than $70 \%$, while the water content in other layers are around $35 \% \sim 50 \%$, and layer I has the lowest water content. In addition, it could be seen from the figure that during the melting period, the water content of layer III and layer IV increases slowly, while that of layer I and layer II decreases gradually.

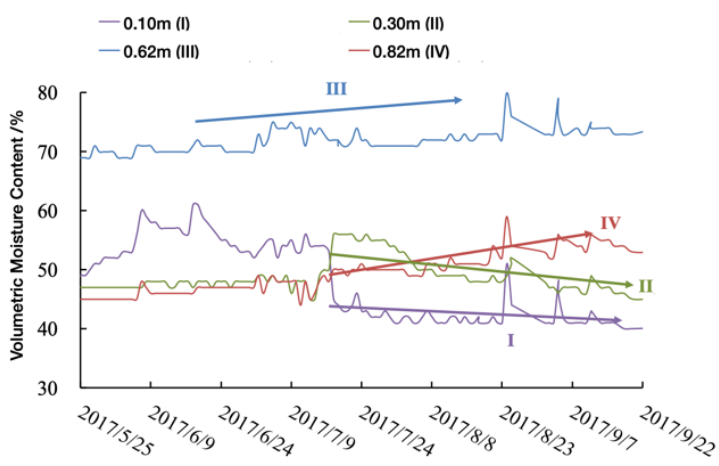

Figure 5. Subgrade moisture curves

The existence of aquifer provides material sources for the frost heave deformation of each layer in cold seasons. The strong freeze-thaw cycles led to the formation of a significant temperature gradient in this region, which provides the necessary driving forces for water transfer from bottom to top. The water content of each layer would also be related to the delamination deformation of each layer. The area with the largest frost heave deformation also accounts for the largest water content.

Hence, although Sentinel-1 InSAR observations provide the frost heave deformation evolution only from the surface of seasonally frozen soil, those time series in-situ monitoring data in deep underground boreholes not only further explains the deformation evolution from InSAR observations, but also provide a better supplement for a more comprehensive mechanism understanding of frost heave deformations.

\section{CONCLUSIONS}

With time series Sentinel-1 InSAR observations, this study realized the characterization of the frost heave deformations in high latitude and deep seasonally frozen soil in Inner Mongolia, and the analysis of the influencing factors of the hydrothermal process with the help of temperature and moisture data from in-situ monitoring.

Time series InSAR observations show that most parts of the highway show obvious deformation with a displacement rate of around $30-60 \mathrm{~mm} / \mathrm{yr}$. What's more, the deformation evolution in this seasonally frozen soil region changes with seasons, demonstrating a notable annual cyclical characteristic and seasonal activity.

The monitoring data of highway water and heat show that the shallow layer of subgrade is affected by obvious freeze-thaw cycle. The temperature monitoring data show that the strong freeze-thaw cycle results in significant temperature gradient on the top of the pavement, which provides the necessary driving force for the water transfer from bottom to top. The water monitoring data show that the aquifers in frozen soil provide abundant water sources for the development of frost heave.

To summarize, the integration of Sentinel-1 InSAR observations and in-situ monitoring data could help to retrieve a comprehensive and reliable characterizations of the frost heave deformations in high latitude and deep seasonally frozen soil, while facilitates to better understand its kinematics and to observe its relationship with environmental factors.

\section{ACKNOWLEDGEMENTS}

This work was supported by the Opening Fund (2019KFJJ-005) of Inner Mongolia Key Laboratory of Road Structure and Materials, Key Laboratory of Transport Industry of Management, Control and Cycle Repair Technology for Traffic Network Facilities in Ecological Security Barrier Area, and also supported by State Key Laboratory of Frozen Soil Engineering (SKLFSE201910) and State Key Laboratory of Geodesy and Earth's Dynamics (Institute of Geodesy and Geophysics, CAS) (SKLGED2019-5-1-E). The Sentinel-1 datasets are copyrighted by ESA.

\section{REFERENCES}

Chang, L., Jin, S., He, X., 2014. Assessment of InSAR atmospheric correction using both MODIS near-infrared and 
infrared water vapor products. IEEE Transactions on geoscience and remote sensing, 52(9), 5726-5735.

Chang, X., Jin, H., Zhang, Y., He, R., Luo, D., Wang, Y., Lü, L., Zhang, Q., 2015. Thermal impacts of boreal forest vegetation on active layer and permafrost soils in northern $\mathrm{Da}$ Xing'anling (Hinggan) Mountains, Northeast China. Arctic, Antarctic, and Alpine Research, 47(2), 267-279.

Chen, F., Lin, H., Li, Z., Chen, Q., Zhou, J., 2012. Interaction between permafrost and infrastructure along the QinghaiTibet Railway detected via jointly analysis of C-and L-band small baseline SAR interferometry. Remote sensing of Environment, 123, 532-540.

Cheng, G., 2001. International achievements of study on frozen soil mechanics and engineering-summary of the International Symposium on Ground Freezing and Frost Action in Soils. Advances in Earth Science, 16(3), 293-299.

Daout, S., Doin, M. P., Peltzer, G., Socquet, A., Lasserre, C., 2017. Large- scale InSAR monitoring of permafrost freezethaw cycles on the Tibetan Plateau. Geophysical research letters, 44(2), 901-909.

Hinkel, K., Doolittle, J., Bockheim, J., Nelson, F., Paetzold, R., Kimble, J., Travis, R., 2001. Detection of subsurface permafrost features with ground- penetrating radar, Barrow, Alaska. Permafrost and Periglacial Processes, 12(2), 179-190.

Jia, Y., Kim, J.-W., Shum, C., Lu, Z., Ding, X., Zhang, L., Erkan, K., Kuo, C.-Y., Shang, K., Tseng, K.-H., 2017. Characterization of active layer thickening rate over the northern Qinghai-Tibetan plateau permafrost region using ALOS interferometric synthetic aperture radar data, 20072009. Remote Sensing, 9(1), 84.

Jin, H., Yu, Q., Lü, L., Guo, D., He, R., Yu, S., Sun, G., Li, Y., 2007. Degradation of permafrost in the Xing'anling Mountains, Northeastern China. Permafrost and Periglacial Processes, 18(3), 245-258.

Li, Z., Fielding, E., Cross, P., Preusker, R., 2009a. Advanced InSAR atmospheric correction: MERIS/MODIS combination and stacked water vapour models. International Journal of Remote Sensing, 30(13), 3343-3363.

Li, Z., Fielding, E. J., Cross, P., 2009b. Integration of InSAR time-series analysis and water-vapor correction for mapping postseismic motion after the 2003 Bam (Iran) earthquake. IEEE Transactions on geoscience and remote sensing, 47(9), $3220-3230$.

Li, Z., Muller, J. P., Cross, P., Fielding, E. J., 2005. Interferometric synthetic aperture radar (InSAR) atmospheric correction: GPS, Moderate Resolution Imaging Spectroradiometer (MODIS), and InSAR integration. Journal of Geophysical Research: Solid Earth, 110(B3).
Li, Z., Tang, P., Zhou, J., Tian, B., Chen, Q., Fu, S., 2015. Permafrost environment monitoring on the Qinghai-Tibet Plateau using time series ASAR images. International Journal of Digital Earth, 8(10), 840-860.

Luo, D., Jin, H., Jin, R., Yang, X., Lü, L., 2014. Spatiotemporal variations of climate warming in northern Northeast China as indicated by freezing and thawing indices. Quaternary International, 349, 187-195.

Tang, W., Liao, M., Yuan, P., 2016. Atmospheric correction in time-series SAR interferometry for land surface deformation mapping-A case study of Taiyuan, China. Advances in Space Research, 58(3), 310-325.

Wu, Q., Zhang, T., Liu, Y., 2010. Permafrost temperatures and thickness on the Qinghai-Tibet Plateau. Global and Planetary Change, 72(1-2), 32-38.

Yao, N., Zhao, Y., Zhang, J., He, H., Si, B., Jiao, R., 2017. Soil Water and Heat Dynamics During Freezing and Thawing Period Under Three Grazing Densities in Grassland of Inner Mongolia. Research of Soil and Water Conservation, 2017, 24(05): 132-138.

Zhang, H., 2019. The study on the frost heave and hydrothermal process of highway in high latitude and deep seasonally frozen soil regions of Inner Mongolia. Journal of Glaciology and Geocryology, 1-15.

Zhang, X., Zhang, H., Wang, C., Tang, Y., Zhang, B., Wu, F., Wang, J., Zhang, Z., 2019. Time-series InSAR monitoring of permafrost freeze-thaw seasonal displacement over QinghaiTibetan Plateau using Sentinel-1 data. Remote Sensing, 11(9), 1000 .

Zorigt, M., Kwadijk, J., Van Beek, E., Kenner, S., 2016. Estimating thawing depths and mean annual ground temperatures in the Khuvsgul region of Mongolia. Environmental Earth Sciences, 75(10), 897. 